\title{
Atividade inseticida de Piper aduncum L. (Piperaceae) sobre Aetalion sp. (Hemiptera: Aetalionidae), praga de importância econômica no Amazonas
}

\begin{abstract}
Wilson Castro SILVA', Joana D’Arc RIBEIRO², Hellen Emilia Menezes de SOUZA³, Raquel da Silva CORREA ${ }^{4}$

RESUMO

O uso de extratos de plantas, em grande parte ainda inexplorada na Amazônia, constitui uma alternativa para o controle de insetos fitófagos, devido o baixo custo operacional, facilidade de preparação, utilização e segurança para o meio ambiente. O objetivo do presente trabalho foi avaliar a ação inseticida de Piper aduncum sobre Aetalion sp. Insetos adultos, coletados em Clitoria fairchildiana, foram separados em grupos de dez indivíduos, colocados em recipientes plásticos e expostos à aplicação tópica de extratos aquosos de folhas e raízes de $P$. aduncum. Os extratos foram aplicados nas concentraçóes de 10, 20 e $30 \mathrm{mg} \cdot \mathrm{ml}^{-1}$. Os grupos de controle tratados com água destilada. Os testes tiveram 48 horas de duração e a cada 12 horas a porcentagem de mortalidade foi avaliada. O experimento se caracterizou num delineamento inteiramente ao acaso com três tratamentos em cinco repetiçóes mais o grupo controle. $\mathrm{O}$ extrato de folhas de $P$. aduncum apresentou menor toxicidade $\left(\mathrm{CL}_{50}=20,9 \mathrm{mg} \cdot \mathrm{ml}^{-1}\right)$ do que o extrato de raízes $\left(\mathrm{CL}_{50}=\right.$ $\left.20,2 \mathrm{mg} \mathrm{ml}^{-1}\right)$, mas não foram estatisticamente distintos. Tanto o extrato aquoso de raízes como o de folhas de $P$. aduncum apresentam atividade inseticida sobre adultos de Aetalion sp. Entretanto, por não causar impacto ambiental durante a coleta, recomenda-se o extrato de folhas em programas de controle alternativo desse inseto.
\end{abstract}

\section{PALAVRAS-CHAVE}

Ação inseticida, plantas tóxicas, controle de pragas, Aetalion, cigarrinha.

\section{Insecticidal activity of Piper aduncum L. (Piperaceae) on Aetalion sp. (Hemiptera: Aetalionidae), plague of economic importance in Amazon}

\begin{abstract}
The use of extracts of plants, usually under exploited in Amazonia, is an alternative to control phytophagous insects due to their low costs, easy preparation, use and environmental safety. The aim of this work was to evaluate the insecticidal action of $\mathrm{P}$. aduncum on Aetalion $s p$. Adult insects collected on the Clitoria fairchildiana were separated in groups of ten individuals into plastic vessels and exposed to topic application of aqueous extracts of leaves and roots of P. aduncum. The extracts were applied at the concentrations of 10,20 and $30 \mathrm{mg} . \mathrm{mt}$ 1 . The control groups treated with distilled water. The tests lasted $48 \mathrm{~h}$ and every $12 \mathrm{~h}$ the mortality rate was evaluated. The experiments were performed in a complete randomized design with three treatments in five replicates more a attest group. The extract of leaves of $\mathrm{P}$. aduncum showed shorter toxicity $\left(C L_{50}=20,9 \mathrm{mg} \cdot \mathrm{ml}^{-1}\right)$ than the extract of roots $\left(C L_{50}=20,2 \mathrm{mg}^{\mathrm{m} \mathrm{m}^{-1}}\right)$, but not statistically different. As much the watery extract of roots as of leaves of $\mathrm{P}$. aduncum show insecticidal activity on adults of Aetalion sp. However, for not causing ambient impact during the collection, sends regards the leaves extract in programs of alternative control of this insect.
\end{abstract}

\section{KEY WORDS}

Insecticidal action, toxic plants, pest control, Aetalion, treehopper.

\footnotetext{
1 Universidade do Estado do Amazonas- UEA-Coordenação do Mestrado em Biotecnologia e Recursos Naturais. Av. Carvalho Leal, 1777, Cachoeirinha, CEP 69065-170. (092) 214 9702, Manaus AM., Brasil.sprinkler@uol.com.br.

2 Instituto Nacional de Pesquisas da Amazônia/ Universidade do Estado do Amazonas. jd@inpa.gov.br (In memoriam).

3 Universidade do Estado do Amazonas/Centro Universitário Nilton Lins. hems@argo.com.br

${ }^{4}$ Instituto Nacional de Pesquisa da Amazônia. raquelatu@hotmail.com
} 


\section{INTRODUÇÃo}

O conhecimento de plantas inseticidas vem despertando atenção e interesse por parte de pesquisadores para desenvolver meios de controle de pragas prejudiciais às culturas (Gonçalves, 1961; Mariconi, 1970; Cruz, 1979).

Piper aduncum (Piperaceae) é uma planta de interesse econômico para a Amazônia e que pode ser usada no controle de pragas. Essa espécie produz um óleo essencial chamado dilapiol, cujo efeito inseticida foi descrito por Maia et al. (1988). Vários estudos têm demonstrado que esta planta, além da importância medicinal, como antiinflamatório, anti-hemorrágico, adstringente, diurético e outros, também apresenta atividade inseticida, bactericida e fungicida (Correa; Penna, 1984; Maia et al., 1988; Vieira, 1991; Veras, 2000; Yuyama, 2000; Morandim et al., 2003; Figueira et al., 2003; Bastos et al., 2003).

Estima-se que aproximadamente 90.000 espécies de insetos sejam consideradas pragas no mundo. Elas provocam grandes prejuízos as principais culturas, podendo proporcionar perdas na produção que variam de 2 a $28 \%$. Entretanto, as pragas das culturas no Brasil acarretam prejuízos na produção com variáveis de 7 a $79 \%$ (Zucchi et al., 1992).

Os insetos sugadores causam vários danos às plantas, os quais podem ser observados nas partes do tecido vegetal. Estes insetos sugam a seiva dos caules, raízes, ramos, folhas e frutos, ocasionando o definhamento da planta, além de injetarem substâncias tóxicas durante a sucção, comprometendo o desenvolvimento normal dos tecidos e a produção. Além desses, danos físicos ao vegetal, outros prejuízos econômicos e ambientais podem ser causados, os quais são comparáveis aos prejuízos indiretos produzidos pelas pragas (Gallo et al., 1988).

Segundo Borror \& Delong (1988), entre esses insetos sugadores encontra-se o Aetalion sp., pertencente à família Aetalionidae, sendo a espécie Aetalion reticulatum, a "cigarrinha dos pomares", a mais conhecida.

A ampla diversidade biológica, em grande parte ainda inexplorada, principalmente de regiōes como a Amazônia, representa um potencial para a pesquisa de novos produtos que poderão vir a substituir os agrotóxicos químicos (Santos, 1998). Assim, o uso de extrato de P. aduncum poderá ser uma alternativa de controle contra insetos fitófagos e, conseqüentemente, viabilizará custos operacionais, ajudando a produzir alimentos mais seguros e protegerá o meio ambiente dos efeitos diversos causados pelos agrotóxicos convencionais, tornando os pequenos agricultores da região Amazônica independentes da aquisição desses produtos.

\section{MATERIAL E MÉTODOS}

Os experimentos e a avaliação da ação inseticida dos extratos de folhas e raízes de $P$. aduncum foram realizados no Instituto Nacional de Pesquisas da Amazônia, no Laboratório de Entomologia Agrícola e na casa-de-vegetação da Coordenação de Pesquisas em Ciências Agronômicas (CPCA) e no Laboratório de Farmacologia da Coordenação de Pesquisas de Produtos Naturais (CPPN), Manaus-AM, Brasil, no período de junho a outubro de 2004.

\section{SELEÇÃO DO MATERIAL BOTÂNICO}

As amostras de $P$. aduncum foram obtidas na estrada AM010, km 24, na margem esquerda da estrada, no sentido Manaus - Rio Preto da Eva. A identificação botânica do material foi feita com base nos caracteres morfológicos, comparando-se o material com outros já identificados no herbário do INPA. Para separar as folhas, foi utilizada tesoura de poda e, para as raízes, um facão. $\mathrm{O}$ material obtido no campo foi acondicionado em sacos plásticos e transportado para o Laboratório de Farmacologia do INPA.

\section{SECAGEM E TRITURAÇÃO DO MATERIAL BOTÂNICO}

As folhas de $P$. aduncum foram acondicionadas em sacos de papel e colocadas em uma estufa, à temperatura de $37^{\circ} \mathrm{C}$, durante sete dias. Em seguida, foram trituradas e acondicionadas em sacos plásticos de três quilos, sendo, posteriormente, armazenadas em geladeira à temperatura de aproximadamente $10^{\circ} \mathrm{C}$, segundo metodologia descrita por Prista et al. (1981), com algumas modificaçōes introduzidas pelo Laboratório de Farmacologia do INPA.

Para a secagem das raízes, adotou-se também a metodologia descrita por Prista et al. (1981), com algumas modificações. As raízes de P. aduncum foram lavadas em água corrente para retirada de terra e colocadas para secar em casa de vegetação à temperatura ambiente, variando de 34 a $40{ }^{\circ} \mathrm{C}$, durante sete dias. Após esse período, as raízes foram cortadas em pedaços de tamanho de $5 \mathrm{x}$ $1 \mathrm{~cm}$ e colocadas novamente para secar em casa de vegetação por mais 24 horas. Após a segunda secagem, foram trituradas e acondicionadas em sacos plásticos de três quilos e, posteriormente, armazenadas em geladeira à temperatura de $10^{\circ} \mathrm{C}$ aproximadamente.

\section{COLETA DOS INSETOS}

Adultos de Aetalion sp. (Hemiptera, Aetalionidae), considerados pragas sugadoras de importância econômica, foram coletados em Clitoria fairchildiana (Leguminosae, Faboideae), localizada na Av. Efigênio Sales, Aleixo, no município de ManausAM. As folhas e os ramos cortados, infestados com insetos, foram colocados em sacos plásticos, transportados para o Laboratório de Entomologia Agrícola do INPA, onde foram acondicionados em gaiolas e preparados para os testes laboratoriais. 


\section{PREPARAÇÃO DO EXTRATO AQUOSO LIOFILIZADO DE FOLHAS DE $P$. aduncum}

Em um frasco mariotte de 4,0 1, contendo 3,5 1 de água destilada, colocou-se $654,1 \mathrm{~g}$ de folhas trituradas de P. aduncum para obtenção, por maceração, durante 72 horas, do extrato aquoso. Após esse período, o extrato foi filtrado e colocado em um outro recipiente de três litros.

Foram usados cinco recipientes de vidro, variando de 7 a 10 $\mathrm{cm}$ de diâmetro e $10 \mathrm{a} 15 \mathrm{~cm}$ de altura, onde o extrato filtrado foi distribuído. Os recipientes foram colocados em liofilizador Freezer dryer-BETA $1-8 \mathrm{~K}$, à temperatura de $-45^{\circ} \mathrm{C}$, onde permaneceram por cinco dias para obtenção do extrato bruto.

\section{PREPARAÇÃO DO EXTRATO AQUOSO LIOFILIZADO DE RAÍZES DE} P. aduncum

Utilizou-se 705,8 g de raízes trituradas de P. aduncum. Para obtenção e liofilização do extrato aquoso, foi realizado o mesmo procedimento para obtenção do extrato aquoso de folhas.

\section{APLICAÇÃO DOS EXTRATOS AQUOSOS DE FOLHAS E RAÍZES DE P. aduncum SOBRE ADULTOS DE Aetalion sp.}

No laboratório, foram realizados ensaios biológicos com 200 insetos adultos de Aetalion sp., separados e distribuídos em vinte recipientes de plástico de $15 \mathrm{~cm}$ de diâmetro $\mathrm{x} 10 \mathrm{~cm}$ de altura, sendo colocados dez insetos em cada recipiente, juntamente com dois pedaços de caules jovens de C. fairchildiana, (com aproximadamente $7 \mathrm{~cm}$ de comprimento $\mathrm{x} 1 \mathrm{~cm}$ de diâmetro), para alimentação e uma porção de algodão umedecido com água. Para vedação do recipiente, a fim de evitar fuga dos insetos, foi utilizado tecido tipo filó, com orifício para permitir o manuseio, sendo este ajustado com uma liga elástica.

Um pulverizador de plástico foi utilizado para aplicação do extrato sobre os insetos. Após a aplicação, as amostras foram deixadas em casa-de-vegetação, à temperatura de $30^{\circ} \pm 5^{\circ} \mathrm{C}$, umidade relativa de $80 \pm 10 \%$.

A mortalidade dos insetos foi avaliada a cada $12 \mathrm{~h}$ durante um total de $48 \mathrm{~h}$, sendo a alimentação e o algodáo umedecido trocados após $24 \mathrm{~h}$.

\section{AVALIAÇÃO INSETICIDA DO EXTRATO DE FOLHAS E RAÍZES DE P. aduncum}

Para avaliar a eficiência dos extratos de folhas e de raízes de $P$. aduncum, os extratos foram preparados e aplicados sobre os insetos nas concentraçōes 10, 20 e $30 \mathrm{mg}^{-\mathrm{ml}^{-1}}$. O grupo controle recebeu aplicação de água destilada.

\section{ANÁLISE ESTATÍSTICA}

Os valores obtidos nos experimentos foram submetidos à análise de variância (ANOVA) (Zar, 1984). Foi usado o delineamento experimental inteiramente ao acaso, com três tratamentos e com cinco repetiçóes e mais o grupo controle, a fim de ser avaliada a mortalidade dos insetos. Os resultados foram expressos pelo parâmetro de Concentração Letal Mediana $\left(\mathrm{CL}_{50}\right)$

Para avaliação da toxicidade aguda, foi usada a ANOVA, onde os valores médios das taxas de mortalidade foram comparados, seguidos pelo teste de Dunnett, que comparou os percentuais de mortalidade obtidos em cada tratamento, para determinar as diferenças significativas com base nas taxas de mortalidade do controle. Para isso, os valores de taxas de mortalidade foram previamente transformados em arcoseno para procedimento da ANOVA.

A análise de Probit (Finney, 1971) foi usada para obtenção dos valores da $\mathrm{CL}_{50}$ e respectivos intervalos de confiança a $95 \%$ (IC-95\%). O programa TOXRAT® foi utilizado para execução das análises de Probit e construção das curvas de dose-resposta. Ressaltando que, mortalidade natural ocorrida no controle abaixo de $10 \%$, previamente, os valores da mortalidade foram corrigidos utilizando a fórmula de Abbott (1925), descrita a seguir:

$$
\begin{aligned}
& \mathrm{Mc}(\%)=\frac{\% \mathrm{Mo}-\% \mathrm{Mt}}{100-\% \mathrm{Mt}} 100, \text { onde: } \\
& \mathrm{Mc}=\text { Mortalidade corrigida } \\
& \mathrm{Mo}=\text { Mortalidade observada } \\
& \mathrm{Mt}=\text { Mortalidade na testemunha }
\end{aligned}
$$

Para comparação de toxicidade entre os extratos de raízes e folhas, os valores dos intervalos de confiança de duas $\mathrm{CL}_{50}$ foram usados, ou seja, valores da $\mathrm{CL}_{50}$ foram considerados estatisticamente diferentes quando não houve sobreposição dos intervalos de confiança a $95 \%$ de probabilidade.

\section{RESULTADOS}

\section{ATIVIDADE INSETICIDA DO EXTRATO AQUOSO DE FOLHAS DE $P$ aduncum SOBRE ADULTOS DE Aetalion sp.}

As percentagens de mortalidade de Aetalion sp., nas concentrações de 10, 20 e $30 \mathrm{mg} \cdot \mathrm{ml}^{-1}$ de extrato aquoso de folhas e raízes de $P$. aduncum e intervalos de avaliação, estão demonstrados na Tabela 1. Observou-se que, no intervalo de 48

Tabela 1 - Mortalidade de Aetalion sp., nas diferentes concentrações de extrato aquoso de folhas e raízes de $P$. aduncum, nos intervalos de tempo avaliados.

\begin{tabular}{cccccccccccc}
\hline \multirow{8}{*}{$\begin{array}{c}\text { Concentração } \\
\text { mg/ml }\end{array}$} & \multicolumn{10}{c}{ Mortalidade (\%) } \\
\cline { 2 - 11 } & \multicolumn{1}{c}{ Folhas Raízes } & Folhas Raízes Folhas Raízes Folhas Raízes Folhas Raízes \\
\hline 10 & 0 & 4 & 12 & 4 & 10 & 8 & 6 & 10 & 28 & 26 \\
20 & 4 & 8 & 14 & 16 & 12 & 4 & 8 & 12 & 38 & 40 \\
30 & 8 & 28 & 36 & 22 & 14 & 18 & 14 & 12 & 72 & 80 \\
controle & 0 & 0 & 0 & 0 & 0 & 2 & 2 & 4 & 2 & 6 \\
\hline
\end{tabular}


h, na concentração de $30 \mathrm{mg} \cdot \mathrm{ml}^{-1}$, os extratos de folhas e raízes induziram a mortalidade de $72 \%$ e $80 \%$, respectivamente.

A Tabela 2 apresenta as diferenças estatísticas de mortalidade média de Aetalion sp., nas concentraçōes de 10, 20 e 30 mg.ml ${ }^{1}$ de extrato aquoso de folhas e raízes de $P$. aduncum, em relação ao controle, no intervalo de tempo de $48 \mathrm{~h}$. Verificou-se que todos os tratamentos, tanto do extrato de folhas como de raízes, foram estatisticamente diferentes dos controles.

As concentraçōes letais medianas $\left(\mathrm{CL}_{50}\right)$, calculadas a partir das médias de mortalidade dos insetos nas concentrações de 10, 20 e $30 \mathrm{mg} \cdot \mathrm{ml}^{-1}$ de extrato aquoso de folhas e raízes de P. aduncum, no intervalo de tempo de $48 \mathrm{~h}$, foram de $20,9 \%$ e $20,2 \%$, respectivamente, com intervalo de confiança de $95 \%$ (Figura $1)$.

A toxicidade aguda dos extratos de folhas e raízes de $P$. aduncum sobre adultos de Aetalion sp. está demonstrada na Tabela 3. Houve sobreposição entre os intervalos de confiança calculados, indicando que, estatisticamente, não houve diferença significativa entre os extratos.

Tabela 2 - Valores médios da mortalidade de Aetalion sp., nas diferentes concentrações de extrato aquoso de folhas e raízes de $P$. aduncum, no intervalo de tempo de 48 horas.

\begin{tabular}{ccc}
\hline \multirow{2}{*}{$\begin{array}{c}\text { Concentração } \\
\left(\mathrm{mg}^{-} \mathrm{m}^{-1}\right)\end{array}$} & \multicolumn{2}{c}{ Mortalidade $(\%)$} \\
\cline { 2 - 3 } & Folhas & Raízes \\
\hline Controle & $2,0( \pm 4,5) \mathrm{a}$ & $6,0( \pm 8,9) \mathrm{a}$ \\
10 & $28,0( \pm 13,0) \mathrm{b}$ & $26,0( \pm 8,9) \mathrm{b}$ \\
20 & $38,0( \pm 27,7) \mathrm{c}$ & $40,0( \pm 22,4) \mathrm{c}$ \\
30 & $72,0( \pm 11,0) \mathrm{d}$ & $80,0( \pm 12,2) \mathrm{d}$ \\
\hline
\end{tabular}

Letras na vertical indicam diferença estatística $\mathrm{a}=0,05$ pelo teste de Dunnett.

Tabela 3 - Toxicidade aguda de extrato aquoso de folhas e raízes de $P$. aduncum para adultos de Aetalion sp. (Concentração Letal Mediana $-\mathrm{CL}_{50}$ )

\begin{tabular}{ccccccc}
\hline & & \multicolumn{2}{c}{$\begin{array}{c}\text { CL50 } \\
(\mathrm{mg} / \mathrm{ml})\end{array}$} & \multicolumn{2}{c}{$\begin{array}{c}\text { 95\% Intervalo de } \\
\text { Confiança (IC) }\end{array}$} & \multicolumn{2}{c}{ IC-Sobreposição } \\
\cline { 3 - 7 } & Extrato & & Inferior & Superior & 1 & 2 \\
\hline 1 & $\begin{array}{c}\text { P. aduncum } \\
\text { (folhas) }\end{array}$ & 20,9 & 16,9 & 25,9 & $*$ & $*$ \\
2 & $\begin{array}{c}\text { P. aduncum } \\
\text { (raízes) }\end{array}$ & 20,2 & 17,1 & 23,9 & $*$ & $*$ \\
\hline
\end{tabular}

\section{DISCUSSÃO}

\section{ATIVIDADE INSETICIDA DOS EXTRATOS AQUOSOS DE FOLHAS E RAÍZES DE $P$. aduncum}

Os extratos aquosos de folhas e raízes de Piper aduncum apresentaram atividade inseticida sobre adultos de Aetalion sp. Provavelmente a mortalidade do inseto ocorreu pela presença do fenilpropanóide dilapiol encontrado nessa planta e que foi isolado

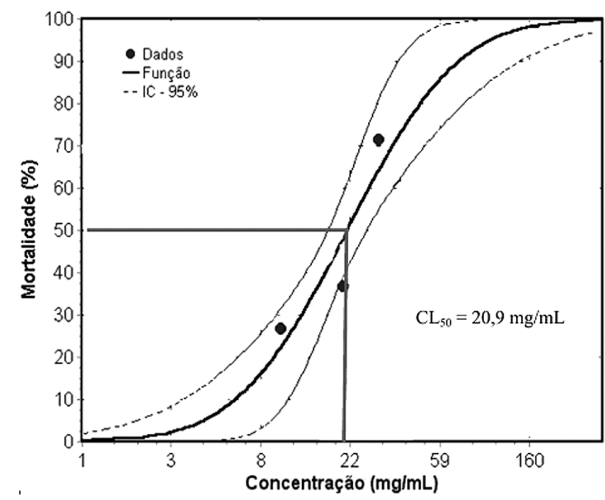

Figura 1 - Concentração Letal Mediana $\left(\mathrm{CL}_{50}\right)$ do extrato aquoso de folhas de $P$. aduncum sobre Aetalion sp., após correção de mortalidade pela fórmula de Abbott.

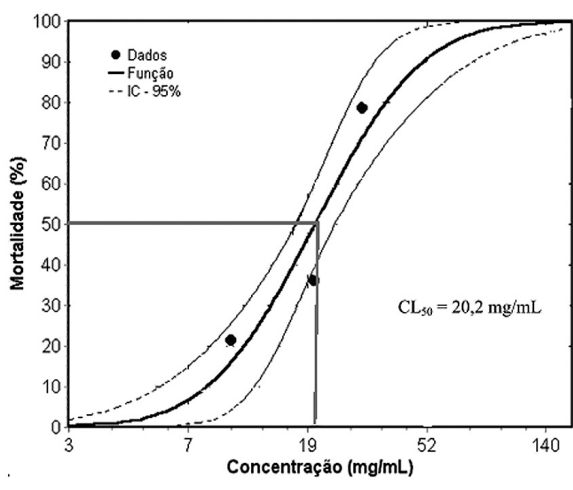

Figura 2 - Concentração Letal $\left(\mathrm{CL}_{50}\right)$ do extrato aquoso de raízes de $P$. aduncum sobre Aetalion sp., após correção da mortalidade pela fórmula de Abbott.

por Oliveira et al. (2004), o qual possui atividade inseticida (Fazolin et al., 2005a).

O extrato aquoso de raízes de $P$. aduncum, na concentração de $30 \mathrm{mg} \cdot \mathrm{ml}^{-1}$, apresentou maior atividade inseticida sobre adultos de Aetalion sp., no intervalo de 48 h, em relação ao extrato aquoso de folhas. A mortalidade observada, utilizando-se o extrato de raízes, mostrou a maior toxicidade dessa parte da planta, da mesma forma que em Lainetti \& Brito (1980).

Bhuiyan et al. (2001) avaliaram os efeitos sinérgicos do dilapiol em larvas de quarto instar de Spodoptera litura utilizando diversos extratos de plantas. Os resultados encontrados por esses autores demonstraram significativa mortalidade das larvas, à semelhança da mortalidade encontrada em adultos de Aetalion sp., quando submetidos a ação dos extratos aquosos de folhas e raízes de $P$. aduncum.

Os resultados obtidos, em estudos realizados por Veras \& Yuyama (2000) com o extrato aquoso de folhas de P. aduncum sobre Crinipellis perniciosa, agente da vassoura-de-bruxa do 
cupuaçuzeiro, indicaram o extrato como uma possível alternativa para o controle mais efetivo e de maior valor agregado desse fungo. Da mesma forma os estudos realizados no controle de adultos de Aetalion sp., alcançaram a mortalidade de 50\% dos insetos induzida pela ação desse extrato, que, além de ser uma alternativa de controle, mantém o equilíbrio ecológico da espécie.

A ação inseticida do extrato aquoso de folhas e raízes de $P$. aduncum, encontrada neste estudo, induziu a mortalidade do inseto fitófago da ordem Hemiptera (adultos de Aetalion sp.). A mesma ação foi observada no trabalho realizado por Fazolin et al. (2005b) em insetos fitófagos da ordem Coleoptera (adultos de Cerotoma tingomarianus), quando utilizou o óleo essencial extraído de folhas e ramos secundários dessa planta.

\section{CONCLUSÕES}

Após análise dos resultados obtidos, concluiu-se que, tanto o extrato aquoso de raízes como o de folhas de $P$. aduncum, apresentaram atividade inseticida sobre adultos de Aetalion sp. Entretanto, por não causar impacto ambiental durante a coleta e pela praticidade de obtenção da matéria-prima, recomenda-se o extrato aquoso de folhas em programas de controle alternativo desse inseto. A análise fitoquímica dos extratos e os testes com as fraçōes dos componentes químicos para identificação e comprovação dos princípios ativos que agem sobre o inseto podem oferecer novas oportunidades de controle efetivo e econômico de adultos de Aetalion sp.

\section{AGRADECIMENTOS}

Os autores agradecem à Universidade do Estado do Amazonas (UEA), ao Instituto Nacional de Pesquisas da Amazônia (INPA) e à Fundação de Amparo à Pesquisa do Estado do Amazonas (FAPEAM).

\section{BIBLIOGRAFIA CITADA}

Abbott, W.S. 1925. A method of computing the effectiveness of an insecticide. Journal of Economic Entomology, 18: 265-266.

Abreu Junior, H.A. 1998. Práticas alternativas de controle de pragas e doenças. EMOPI. São Paulo. 115pp.

Bastos, C.N.; Silva, D.H.M.M.; Guimarães, E.F.; Andrade, E.H.A.; Maia, J.G.S. 2003. Atividade bactericida e composição de óleos essenciais de Piper spp. Documentos, IAC, Campinas. 74pp.

Correa, M.P; Penna, L.A. 1984. Dicionário das plantas úteis do Brasil e das exóticas cultivadas. Instituto Brasileiro de Desenvolvimento Florestal. Rio de Janeiro. 138pp.

Cruz, G.L. 1979. Dicionário das plantas úteis do Brasil. Civilização Brasileira. Rio de Janeiro. 587pp.

Figueira, G.M.; Duarte, M.C.T.; Silva, C.A.L.; Delarmelina, C. 2003. Atividade antimicrobiana do extrato e do óleo essencial de Piper $s p p$ cultivadas na coleção de germoplamas do CPQBA-Unicamp, Hortic. Brás., 21(2): 403.
Finney, D.J. 1971. Probit analysys. 3th ed. Cambridge University Press, London. 25pp.

Fazolin, M.; Estrela, J.L.V.; Catani, V.; De lima, M.S.; Alécio, M.R. 2005. Toxicidade do óleo de Piper aduncum L. a adultos de Cerotoma tingomarianus Bechyné (Coleoptera: Chrysomelidae). Neotrop. Entomol., 34(3): 485-489.

Gonçalves, C.R. 1961. O gênero Acromyrmex no Brasil. Studia Ent., 4 (1-4): 113-180.

Lainetti R.; Brito, N.R.S. 1980. A saúde pelas plantas e ervas do mundo inteiro. Tecnoprint. Rio de Janeiro. 163pp.

Maia, J.G.S.; Zohhbi, M.G.B.; Andrade, E.H.A.; Santos, A.S.; Silva, M.H.L.; Luz, A.I.R.; Bastos, C.N. 1998. Constituents of the essential oil of Piper aduncum L. growing wild in the Amazon region. Flavour and Fragrance Journal, 13: 269-272.

Mariconi, F.A.M. , 1970. As saúvas. Agronômica Ceres. São Paulo. $167 \mathrm{pp}$.

Matos, J.M.D. 1970. As plantas que curam também podem matar. Edições UFC. Fortaleza. 128pp.

Morandim, A.A.; Navickiene, H.M.D.; Regasini, L.O.; Cordon, T.; Ferri, A.F.; Agripino, D.; Cavalheiro, A.J.; Lopes, M.N.; Marques, M.O.M.; Young, M.C.M.; Kato, M.J.; Bolzani, V.S.; Furlan, M. 2003. Constituição e atividade antifúngica dos óleos essenciais das folhas e caules de Piper aduncum L, P. arboreum Aublet e P. tuberculatum Jacq e dos frutos de P. aduncum L. e P. tuberculatum Jacq. Documentos, IAC, Campinas. 74pp.

Noda, H. 2002. Duas décadas de contribuiçôes do INPA a pesquisa agronômica no trópico úmido. INPA/MCT. Manaus. 329pp.

Penteado, S.R. 2000. Defensivos alternativos e naturais. 2.ed. Grafimagem. São Paulo. 90pp.

Pimentel, D.; Acquail, H.; Bilton, M. 1992. Environmental and social costs of pesticide use. Biociense, 42 (10): 750-760.

Prista, L.N.; Alves, A.C.; Morgado, R.M.R. 1981. Técnica farmacêutica e farmácia galênica. 3.ed.: Calouste Gulbenkian. Lisboa. v.1. 147pp.

Ribeiro, J.D.; Castro, A.P.; Tavares, R. 2000. Uso de plantas tóxicas no controle de formigas cortadeiras (Hymenoptera; Formicidae) no Amazonas. In: Congresso Brasileiro de Defensivos Agrícolas Naturais. Resumos. Fortaleza, Brasil. p. 53

Santos, J.H.R.; Gadelha, J.W.; Pimentel. J.V.F.; Júlio, P.V.M.R. 1988. Controle alternativo de pragas e doenças. Fortaleza: EUFC. 227pp.

Santos, L.G. (1998). Biodiversidade e políticas públicas. In: Fatheuer, T. Arroyo. J.C.; Machado, J.A. Relatos e reflexóes a partir do Simpósio Internacional Amazônia: Estratégias de Desenvolvimento Sustentável em Debate. NAEA/UFPA. Belém. pp 63-85.

Toxrat ${ }^{\circledR}$. 2003. Software for statistical analysis of biotests. Germany: ToxRat solution GmbH, 1CD-ROM.

Véras, S.M; Yuyama, K. 2000. Controle da vassoura-de-Bruxa do cupuaçuzeiro por meio de extrato de Piper Aduncum L. In: Congresso Brasileiro de Defensivos Agrícolas Naturais. Resumos. Fortaleza, Brasil. 32pp. 
Vieira, L.S. 1991. Manual de medicina popular: a fitoterapia da Amazônia. Faculdade de Ciências Agrárias do Pará. Belém. 248pp.

Zar, J.H.1984. Biostatistical analysis. 2nd ed. Englewood Cliffs, NJ: Prentice-Hall, 718pp.

Zucchi, R.A.; Vendramim, J.D.; Berti Filho, E. 1992. Importância dos insetos e manejo de pragas. In: Fundação de Estudos Agrários Luiz de Queiroz. Curso de entomologia aplicada à agricultura. Ed. Ceres. Piracicaba. p.1-3.

Recebido em 01/06/2005

Aceito em 26/03/2007 